\title{
Flow-Injection Potentiometry by Poly(vinyl chloride)-Membrane Electrodes with Diphosphoryl-dicarboxylicacid-p-tert-butylcalix[4] arene Ionophore for the Determination of Th(IV) Ions
}

\author{
Farhang Mizani, ${ }^{* 1 \dagger}$ Mojtaba Shamsipur, ${ }^{* 2}$ Mohammad R. YAfTIAn, ${ }^{* 3}$ and Dominique MatT $* 4$ \\ *1 Department of Chemistry, Faculty of Science, Payame-noor University, Iran \\ *2 Department of Chemistry, Faculty of Science, Razi University, Kermanshah, Iran \\ *3 Phase Equilibria Research Laboratory, Department of Chemistry, Faculty of Science, Zanjan University, \\ Zanjan, Iran \\ *4 Chimie Inorganique Moléculaire Laboratory, Louis Pasteur University, Strasbourg, France
}

\begin{abstract}
A new coated ion-selective electrode for the determination of trace thorium ions by flow-injection potentiometry (FIP) has been developed. A poly(vinyl chloride) (PVC)-based membrane was coated on a graphite electrode. The optimum membrane contained $5 \mathrm{wt} \%$ diphosphoryl-dicarboxylicacid-p-tert-butylcalix[4]arene (L) as the ionophore, $59 \mathrm{wt} \%$ dioctyl phthalate (DOP), $33 \mathrm{wt} \% \mathrm{PVC}$ and $3 \mathrm{wt} \%$ additive sodium tetraphenylborate. The response was linear from $2.0 \times 10^{-7}$ to $1.0 \times 10^{-2} \mathrm{M}$ with a slope of $13.9 \mathrm{mV}$ decade $^{-1}$ and a limit of detection of $9.0 \times 10^{-8} \mathrm{M}$. The pH-independent region ranged from 3.15 to 6.5 , and the lifetime was longer than 8 weeks when used in the flow injection analysis (FIA) system. Selectivity coefficients for several ions were obtained by the separate solutions method. Results showed that, for all cations used, the selectivity coefficients were in the order of $10^{-3}$, or smaller. The flow cell is simple to construct and free from memory effect problems over long periods of use. The proposed sensor was successfully applied to the direct determination of thorium in both real and synthetic samples.
\end{abstract}

(Received August 11, 2012; Accepted November 5, 2012; Published March 10, 2013)

\section{Introduction}

Thorium, as an important radioactive element widely distributed over the earth's crust, not only has extensive applications in industry, e.g., optics, radio, gas mantle, aeronautics and aerospace, metallurgy and chemical industry, and material, but is also used for energy, for example, as nuclear energy for electricity production in power plants. ${ }^{1}$ However, thorium is a toxic heavy metal that is extremely mobile, and once having entered living bodies will provoke inner irradiation (especially due to $\gamma$-active decay products), having as a final result the appearance of cancer. ${ }^{2}$ Also, thorium and its compounds are hazardous, causing environmental problems. In view of the extensive application, toxicity, and hazard, the development of reliable methods for the separation, monitoring, and recovery of thorium in environmental and geological samples is of particular significance. ${ }^{3}$ Owing to thorium's trace concentration in nature, and its presence in complex matrices, the direct determination of thorium is still difficult. ${ }^{4}$

The introductions of new ion-selective electrodes have caused a fundamental development in potentiometry over the past two decades. Extensive research work has been directed towards the preparation of molecular carriers possessing electrical neutrality, lipophilic character and a capability to selectively and reversibly bind given metal ions to induce a selective permeation of one

† To whom correspondence should be addressed.

E-mail: Farhangmizani@yahoo.com type of metal ion through the membranes of the electrodes. ${ }^{5}$

However, despite the urgent need for thorium-selective sensors for the potentiometric monitoring of $\mathrm{Th}^{4+}$ ions, there have appeared only limited reports in this respect in the literature. ${ }^{6,7}$ It should be noted that these reported electrodes suffer from one or more of the following drawbacks: (i) lack of stability and selectivity, (ii) limited linear concentration range and (iii) small range of the working $\mathrm{pH}$. Moreover, to the best of our knowledge, there has been no previous report about the determination of $\mathrm{Th}^{4+}$ in a flow-injection potentiometry system. Marocyclic ligands have the ability to discriminate among closely related metal ions based on their radii (ring size effect). ${ }^{8,9}$ In recent years, we have reported the successful use of some different ion carriers in the construction of poly(vinyl chloride) (PVC)-based selective electrodes for Uranyl(II), ${ }^{10,11} \mathrm{Cu}(\mathrm{II}),{ }^{12}$ $\mathrm{Cr}(\mathrm{III}),{ }^{13} \mathrm{Co}(\mathrm{II}),{ }^{14}$ and some other ionic species.

In this paper, we first report on the preparation of a PVC membrane (PME) and coated graphite electrodes (CGE) based on a new functionalized calix[4]arene (Fig. 1), which exhibits significantly high selectivity to $\mathrm{Th}^{4+}$ ions over alkali, alkaline earth and several transition-metal ions. Then, the successful use of the prepared proper detection system in flow-injection potentiometry (FIP) of $\mathrm{Th}^{4+}$ ions is discussed.

\section{Experimental}

Reagents
Reagent-grade potassium tetrakis[3,5-bis(trifluoromethyl)- 


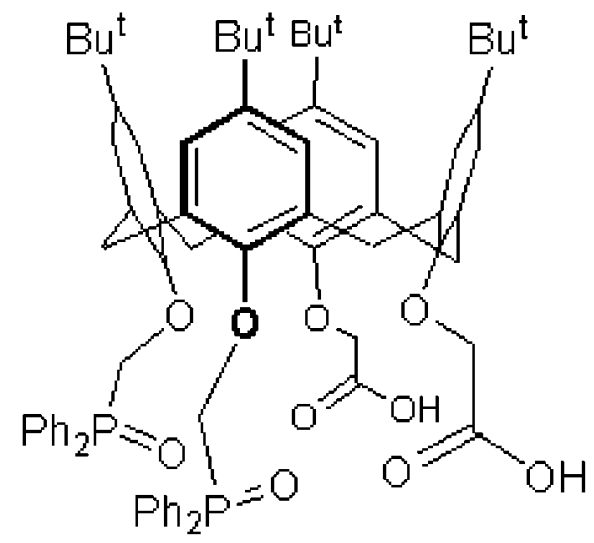

Fig. 1 Structure of ligand L.

phenyl]borate (PTKB) (from Sigma-Aldrich), oleic acid (OA), $o$-nitrophenyl octyl ether (NPOE), dibutyl phthalate (DBP), benzylacetate (BA), tetrahydrofuran (THF) and high relative molecular-weight PVC (all from Merck) were used as received. Nitrate salts of all cations with the highest purity available were purchased from Merck, and used without any further purification, except for vacuum drying over $\mathrm{P}_{2} \mathrm{O}_{5}$. Triply distilled deionized water was used throughout.

\section{Preparations of calixarene}

Diphosphoryl-dicarboxylic acid-p-tert-butylcalix[4]arene was prepared by saponification of the corresponding diethyl ester with $\mathrm{NaOH} / \mathrm{EtOH}$, followed by acidification with $\mathrm{HCl}$, as reported elsewhere. ${ }^{15}$

\section{Preparation of electrodes}

A membrane solution was prepared by thoroughly dissolving $5 \mathrm{mg}$ of ligand, $33 \mathrm{mg}$ of powdered PVC, $3 \mathrm{mg}$ of an additive and $59 \mathrm{mg}$ of a plasticizer in $5 \mathrm{ml}$ of THF. The resulting clear mixture was evaporated slowly until an oily concentrated mixture was obtained.

A Pyrex tube ( $3 \mathrm{~mm}$ o.d. on top) was dipped into the mixture for about $10 \mathrm{~s}$, so that a nontransparent membrane of about $0.3 \mathrm{~mm}$ thick was formed. The tube was then pulled out from the mixture and kept at room temperature for about $1 \mathrm{~h}$. The tube was then filled with an internal filling solution $(1.0 \times$ $10^{-3} \mathrm{M} \mathrm{Th}^{4+}$ ion). The electrode was finally conditioned for $20 \mathrm{~h}$ by soaking in $1.0 \times 10^{-2} \mathrm{M}$ of $\mathrm{Th}^{4+}$. A silver/silver chloride electrode was used as an internal reference electrode.

To prepare the CGE, spectroscopic-grade graphite rods of $10 \mathrm{~mm}$ long and $3 \mathrm{~mm}$ in diameter were used. A shielded copper wire was glued to one end on a graphite rod, and the electrode was sealed in to the end of a PVC tube of about the same diameter with epoxy resin. The working surface of the electrode was polished with fine alumina slurries on a polishing cloth, sonicated in distilled water and dried in air. The polished graphite electrode was dipped into the membrane solution mentioned above, and the solvent was evaporated. A membrane was formed on the graphite surface, and the electrode was allowed to stabilize overnight. The electrode was finally conditioned by soaking in a $1.0 \times 10^{-2} \mathrm{M}$ solution of $\mathrm{Th}^{4+}$ for $48 \mathrm{~h}$.

\section{Emf measurements}

Emf measurements with the PME and CGE were carried out with the following cell assemblies:

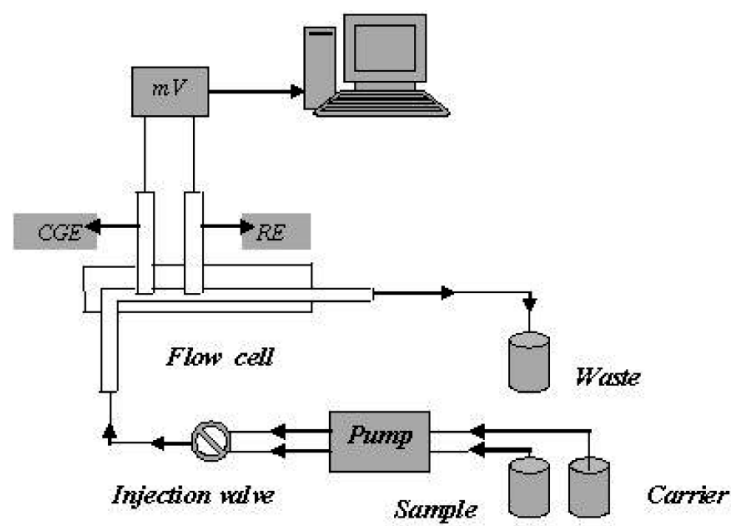

Fig. 2 Manifold of the flow-injection potentiometric system.

PME: $\mathrm{Ag}-\mathrm{AgCl}|\mathrm{KCl}(3 \mathrm{M})|$ internal solutions, $1.0 \times 10^{-3} \mathrm{M}$ $\mathrm{Th}^{4+} \mid \mathrm{PVC}$ membrane|test solutions $\mid \mathrm{Hg}-\mathrm{Hg}_{2} \mathrm{Cl}_{2}, \mathrm{KCl}$ (saturated) CGE: $\mathrm{Hg}-\mathrm{Hg}_{2} \mathrm{Cl}_{2}, \mathrm{KCl}$ (saturated)|test solutions/membrane| graphite surface

Emf observations were made relative to a double-junction saturated calomel electrode (SCE, Philips) with the chamber filled with an ammonium nitrate solution. A double-junctions silver/silver chloride electrode (Metrohm) containing a $3 \mathrm{M}$ solution of $\mathrm{KCl}$ was used as an internal reference electrode. Activities were calculated according to the Debye-Hückel procedure. ${ }^{16-22}$

A schematic representation of a manifold of the flow-injection potentiometric analysis system employed is shown in Fig. 2. A home-made polyacrylamide $70-\mu \mathrm{L}$ flow cell was used. The cell contained coated graphite thorium ISE with an effective surface area of $5 \mathrm{~mm}^{2}$ and a commercial $\mathrm{Ag} / \mathrm{AgCl}$ reference electrode (Metrohm) with a double junction having a terminal tube diameter of $2.5 \mathrm{~mm}$. A 12-channel peristaltic pump (Desaga) was used to continuously draw the solution through the cell. A low-pressure rotary injection valve (Model 5020 Rheodyne four way rotary valve, USA) was used in the flow system.

\section{Results and Discussion}

\section{Preliminary study}

To study the potential response and the selectivity of the calixarene L for different metal ions, it was used as a neutral carrier to prepare PVC membrane electrodes for a wide variety of cations, including alkali, alkaline earth, transitions and heavy metal ions. The potential responses of various ion-selective electrodes based on calixarene are shown in Fig. 3.

As can be seen from Fig. 3, except for the $\mathrm{Th}^{4+}$ ion selective electrode, in all other cases the slope of the corresponding potential-pM plots was much lower than the expected Nernstian slopes of 59, 29.5, 19.5 and $15 \mathrm{mV}$ per decade for mono-, di-, tri- and tetra-valent cations, respectively, although over a very limited concentration range. As is obvious from the obtained results, the $\mathrm{Th}^{4+}$ ion with the most sensitive response over a wide concentration range seems to be suitably determined with the membrane electrode based on calixarene. This is most probably due to the highly selective behavior of the inophore $\mathrm{L}$ for $\mathrm{Th}^{4+}$ over other metal ions. 


\section{Membrane composition}

It is well known that the response behavior and selectivity obtained for a given electrode depend significantly on some important features of the PVC membrane, such as the nature and amount of the ionophore, the properties of the plasticizer, the plasticizer/PVC ratio and, especially, the nature and amount of the additive used..$^{8,14,16-28}$ Thus, different aspects of the membrane preparations based on calixarene $\mathrm{L}$ for $\mathrm{Th}^{4+}$ were optimized; the results are presented in Table 1. As can be seen, increasing amounts of the ionophore resulted in membrane electrodes that exhibited improved slopes and a larger linear range.

Approximately 5\% (w/w) of the ligand offered electrodes with almost Nernstian responses towards $\mathrm{Th}^{4+}(13-16 \mathrm{mV}$ per decade) over a wide range of $\mathrm{Th}^{4+}$ concentration. However, a further increase in the amount of ionophore showed no clear advantage in terms of the response slope and detection limit of the electrode. Therefore, membranes doped with $5 \%(\mathrm{w} / \mathrm{w})$ of the ionophore were used for further studies.

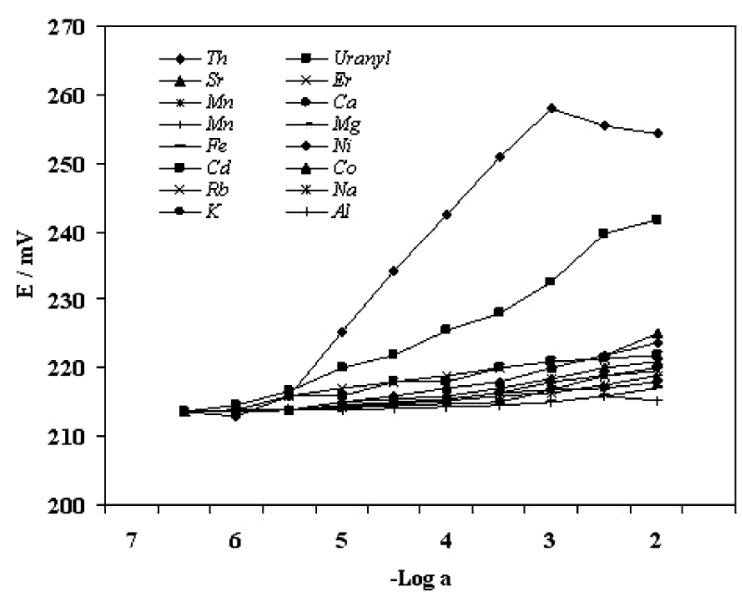

Fig. 3 Potential responses of various ion-selective electrodes based on calix[4]arene $\mathrm{L}$.
It is reported that the response characteristics of ion-selective electrodes are largely affected by the nature and the amount of the plasticizer used..$^{8,14,16-28}$ This is due to the influence of the plasticizer on the dielectric constant of the membrane phase, the mobility of the ionophore molecules and the state of the ligands. ${ }^{23,24}$ As can be seen from Table 1, among four different plasticizers used, DOP resulted in the best response slope and linearity.

It should be noted that the presence of lipophilic anionic additives in cation-selective membranes not only diminished the ohmic resistance, and enhanced the response behavior and selectivity, but also increased where the extraction capability was poor, and increased the sensitivity of the membrane electrode. ${ }^{26-28}$ Moreover, additives may catalyze the exchange kinetics at the sample-membrane interface. ${ }^{23}$ From the data presented in Table 1, it can be seen that the addition of sodium tetraphenylborate (NaTPB) will increase the sensitivity of the electrode response considerably. The use of $3 \%(\mathrm{w} / \mathrm{w})$ of NaTPB resulted in a Nernstian behavior of the electrodemembrane. The plasticizer/PVC ratios of $1.5-2$ were examined, and the membranes prepared with a plasticizer/PVC ratio of about 1.78 were found to have the best sensitivity and the widest linear range (Table 1). As is obvious from Table 1, membrane number 12 with a ligand:NaTPB:PVC:NPOE percent ratio of 5:3:33:59 resulted in a Nernstian behavior of the membrane electrode over a wide concentration range.

The optimum conditioning time for PME and CGE in a $1.0 \times$ $10^{-2} \mathrm{M}$ Th(IV) solution was found to be 24 and $48 \mathrm{~h}$, respectively. They then generated a stable potential when placed in contact with $\mathrm{Th}^{4+}$ solutions.

The critical response characteristics of the proposed electrodes were assessed according to the IUPAC recommendation. ${ }^{29}$ The emf response of PME, CGE and FIP shown in Fig. 4 indicate their Nernstian behavior over a wide concentrations range.

\section{Response time}

For analytical applications, the response time of a membrane sensor is an important factor. The static response time of the electrode tested by measuring the average time required to achieve a potential within $1 \mathrm{mV}$ of the final steady state potential

Table 1 Optimization of the membrane ingredients

\begin{tabular}{|c|c|c|c|c|c|c|c|}
\hline \multirow{2}{*}{ No. } & \multicolumn{4}{|c|}{ Composition, \% } & \multirow{2}{*}{$\begin{array}{c}\text { Slope/ } \\
\text { mV decade }{ }^{-1}\end{array}$} & \multirow{2}{*}{$\begin{array}{c}\text { Concentration range/M } \\
\text { (CGE) }\end{array}$} & \multirow{2}{*}{$\begin{array}{l}\mathrm{DL} / \mathrm{M} \\
(\mathrm{CGE})\end{array}$} \\
\hline & PVC & Plasticizer & $\mathrm{L}$ & Additive & & & \\
\hline 1 & 33 & DOP, 67 & - & - & 0 & - & - \\
\hline 2 & 33 & BA, 64 & 3 & - & 7.5 & $3.0 \times 10^{-4}-1.5 \times 10^{-2}$ & $1.6 \times 10^{-4}$ \\
\hline 3 & 33 & DBP, 64 & 3 & - & 9.6 & $5.2 \times 10^{-5}-1.2 \times 10^{-3}$ & $2.5 \times 10^{-5}$ \\
\hline 4 & 33 & NPOE, 64 & 3 & - & 8.4 & $2.7 \times 10^{-4}-1.0 \times 10^{-2}$ & $9.6 \times 10^{-5}$ \\
\hline 5 & 33 & DOP, 64 & 3 & - & 11.3 & $1.2 \times 10^{-5}-2.7 \times 10^{-3}$ & $8.8 \times 10^{-5}$ \\
\hline 6 & 33 & DOP, 62 & 5 & - & 12.7 & $1.6 \times 10^{-5}-1.1 \times 10^{-3}$ & $9.4 \times 10^{-5}$ \\
\hline 7 & 33 & DOP, 60 & 7 & - & 11.9 & $1.9 \times 10^{-5}-1.6 \times 10^{-3}$ & $8.5 \times 10^{-6}$ \\
\hline 8 & 33 & DOP, 57 & 5 & OA, 5 & 13.4 & $5.2 \times 10^{-5}-3.0 \times 10^{-3}$ & $1.5 \times 10^{-6}$ \\
\hline 9 & 33 & DOP, 52 & 5 & OA, 10 & 13.1 & $3.6 \times 10^{-5}-4.0 \times 10^{-3}$ & $2.2 \times 10^{-6}$ \\
\hline 10 & 33 & DOP, 47 & 5 & $\mathrm{OA}, 15$ & 12.6 & $2.0 \times 10^{-5}-3.0 \times 10^{-3}$ & $9.5 \times 10^{-6}$ \\
\hline 11 & 33 & DOP, 60 & 5 & NaTPB, 2 & 14.1 & $7.0 \times 10^{-8}-1.0 \times 10^{-3}$ & $5.1 \times 10^{-8}$ \\
\hline 12 & 33 & DOP, 59 & 5 & NaTPB, 3 & 15.1 & $5.0 \times 10^{-8}-1.0 \times 10^{-3}$ & $3.7 \times 10^{-8}$ \\
\hline 13 & 33 & DOP, 58 & 5 & NaTPB, 4 & 14.9 & $9.4 \times 10^{-8}-1.0 \times 10^{-3}$ & $6.6 \times 10^{-8}$ \\
\hline 14 & 33 & DOP, 60 & 5 & PTKB, 2 & 13.8 & $1.5 \times 10^{-6}-2.0 \times 10^{-2}$ & $8.4 \times 10^{-7}$ \\
\hline 15 & 33 & DOP, 59 & 5 & PTKB, 3 & 14.4 & $1.3 \times 10^{-6}-2.0 \times 10^{-2}$ & $7.9 \times 10^{-7}$ \\
\hline 16 & 33 & DOP, 58 & 5 & PTKB, 4 & 13.7 & $5.0 \times 10^{-6}-4.0 \times 10^{-2}$ & $1.7 \times 10^{-6}$ \\
\hline 17 & 33 & BA, 59 & 5 & NaTPB, 3 & 11.4 & $1.0 \times 10^{-7}-1.0 \times 10^{-2}$ & $9.3 \times 10^{-8}$ \\
\hline 18 & 33 & DBP, 59 & 5 & NaTPB, 3 & 12.1 & $9.2 \times 10^{-8}-1.2 \times 10^{-2}$ & $7.6 \times 10^{-8}$ \\
\hline 19 & 33 & NPOE, 59 & 5 & NaTPB, 3 & 12.9 & $6.5 \times 10^{-7}-3.0 \times 10^{-2}$ & $2.2 \times 10^{-7}$ \\
\hline
\end{tabular}


upon successive immersion of a series of $\mathrm{Th}^{4+}$ ions, each having a tenfold difference in the concentrations, was within $<10 \mathrm{~s}$ and $<8 \mathrm{~s}$ for PME and CGE, respectively, for $\mathrm{Th}^{4+}$ concentrations of $<1.0 \times 10^{-3} \mathrm{M}$.

\section{pH effect}

The influences of the $\mathrm{pH}$ of the test solution, adjusted by either $\mathrm{HCl}$ or $\mathrm{NaOH}$ solutions, on the potential response of the CGE in the presence of $1.0 \times 10^{-4} \mathrm{M} \mathrm{Th}^{4+}$ ion are shown in Fig. 5. As can be seen, the results depict that the potential remains fairly constant in the $\mathrm{pH}$ range of $3.15-6.5$, and beyond this range it changes considerably. At higher $\mathrm{pH}$ values, hydroxy complexes of $\mathrm{Th}^{4+}$ can be formed, and the response is decreased, as expected. On the other hand, the increased response at lower $\mathrm{pH}$ values could be due to protontion of the calix[4]arene L.

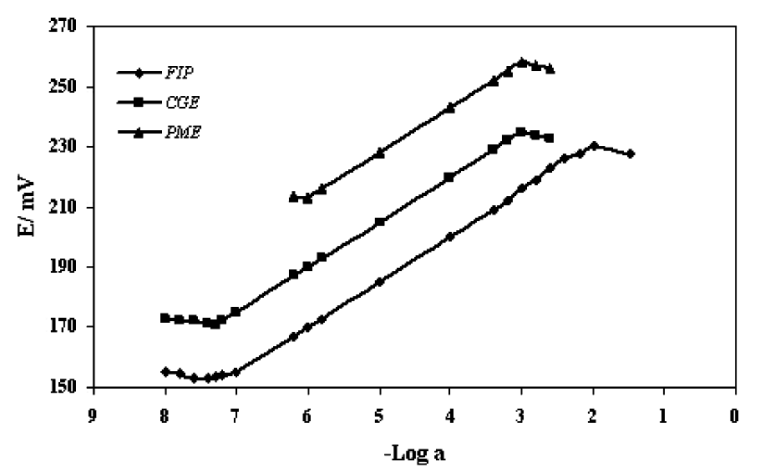

Fig. 4 Calibration curve of the $\mathrm{Th}^{4+}$ ion selective electrode linear range of $5.0 \times 10^{-8}-1.0 \times 10^{-3} \mathrm{M}$ for CGE , $1.0 \times 10^{-6}-1.0 \times 10^{-3} \mathrm{M}$ for PME and $2.0 \times 10^{-7}-1.0 \times 10^{-2} \mathrm{M}$ for FIP.

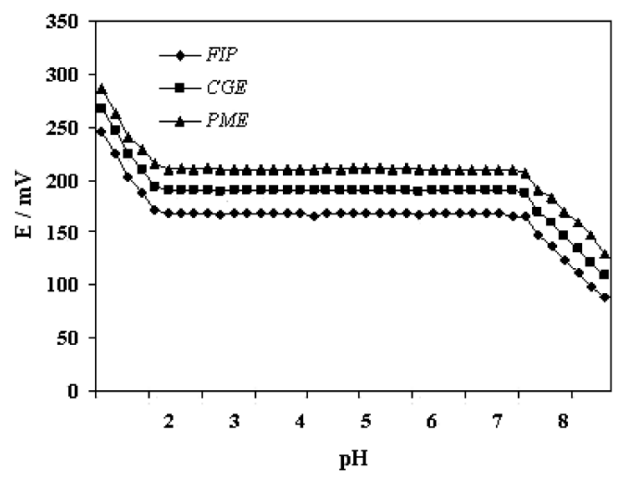

Fig. 5 Influences of the $\mathrm{pH}$ of the test solution on the potential response of the PME, CGE and FIP in the presence of $1.0 \times 10^{-4} \mathrm{M}$ $\mathrm{Th}^{4+}$.

\section{Effect of the internal solution}

The influence of the concentration of the internal solution on the potential response of the PME was investigated. The $\mathrm{Th}^{4+}$ concentration was changed from $1.0 \times 10^{-4}$ to $1.0 \times 10^{-2} \mathrm{M}$, and emf-pTh ${ }^{4+}$ plots were obtained. It was found that the concentration of the internal solution has a negligible effect on the potential response of the electrode, except for an expected change in the intercept of the resulting plot. A $1.0 \times 10^{-3} \mathrm{M}$ concentration of the references solution is quite appropriate for a smooth functioning of the polymeric membrane system. The prepared PME, CGE and FIP could be used frequently for at least 12, 22 and 8 weeks, respectively, without any measurable divergence.

\section{Selectivity coefficients}

The influence of interfering ions on the potential response behavior of the ion-selective membrane electrodes is usually described in terms of the selectivity coefficient. ${ }^{30}$ Potentiometric selectivity coefficients describing the preference by the membrane for an interfering ion $\mathrm{M}^{\mathrm{n}+}$ relative to $\mathrm{Th}^{4+}$ for PME, CGE and FIP were determined by the separate solutions method; ${ }^{30}$ and the resulting values are listed in Table 2.

The selectivity coefficient patterns presented in Table 2 clearly indicate that the electrodes were highly selective to $\mathrm{Th}^{4+}$ over other cations tested. As can be seen, except for the case of the $\mathrm{UO}_{2}{ }^{2+}$ ion, the selectivity coefficients are in the order of $10^{-3}$ or lower, which seems to indicate that these cations have negligible impact on the functionality of the prepared $\mathrm{Th}^{4+}$ sensors.

The data given in Table 2 revealed that, in most cases, the selectivity coefficients obtained for the coated graphite electrode are lower than those for the polymeric membrane electrode,

Table 2 Selectivity coefficient of various interfering ions

\begin{tabular}{lccc}
\hline \multirow{2}{*}{$\begin{array}{c}\text { Interfering } \\
\text { ion }\end{array}$} & \multicolumn{3}{c}{ Selectivity coefficient } \\
\cline { 2 - 4 } & $\mathrm{PME}$ & $\mathrm{CGE}$ & $\mathrm{FIP}$ \\
\hline $\mathrm{UO}_{2}{ }^{2+}$ & $7.3 \times 10^{-2}$ & $2.1 \times 10^{-2}$ & $1.2 \times 10^{-2}$ \\
$\mathrm{Sr}^{2+}$ & $5.5 \times 10^{-3}$ & $1.7 \times 10^{-3}$ & $8.9 \times 10^{-4}$ \\
$\mathrm{Eu}^{2+}$ & $3.5 \times 10^{-3}$ & $7.6 \times 10^{-4}$ & $5.5 \times 10^{-4}$ \\
$\mathrm{Mn}^{2+}$ & $7.7 \times 10^{-3}$ & $2.7 \times 10^{-3}$ & $9.8 \times 10^{-4}$ \\
$\mathrm{Ca}^{2+}$ & $4.6 \times 10^{-3}$ & $1.5 \times 10^{-3}$ & $8.5 \times 10^{-4}$ \\
$\mathrm{Mg}^{2+}$ & $2.9 \times 10^{-3}$ & $9.2 \times 10^{-4}$ & $6.1 \times 10^{-4}$ \\
$\mathrm{Fe}^{2+}$ & $8.7 \times 10^{-3}$ & $2.5 \times 10^{-3}$ & $1.3 \times 10^{-3}$ \\
$\mathrm{Ni}^{2+}$ & $8.4 \times 10^{-3}$ & $6.9 \times 10^{-3}$ & $3.3 \times 10^{-4}$ \\
$\mathrm{Cd}^{2+}$ & $9.2 \times 10^{-4}$ & $4.1 \times 10^{-4}$ & $1.9 \times 10^{-4}$ \\
$\mathrm{Co}^{2+}$ & $3.3 \times 10^{-4}$ & $1.2 \times 10^{-4}$ & $9.2 \times 10^{-5}$ \\
$\mathrm{Rb}^{+}$ & $4.1 \times 10^{-3}$ & $9.6 \times 10^{-4}$ & $4.6 \times 10^{-4}$ \\
$\mathrm{Na}^{+}$ & $2.6 \times 10^{-3}$ & $7.5 \times 10^{-4}$ & $2.9 \times 10^{-4}$ \\
$\mathrm{~K}^{+}$ & $3.6 \times 10^{-3}$ & $1.9 \times 10^{-4}$ & $1.1 \times 10^{-4}$ \\
$\mathrm{Al}^{3+}$ & $7.1 \times 10^{-4}$ & $2.1 \times 10^{-4}$ & $7.6 \times 10^{-4}$ \\
$\mathrm{Cr}^{3+}$ & $6.7 \times 10^{-4}$ & $3.7 \times 10^{-4}$ & $2.2 \times 10^{-4}$ \\
\hline
\end{tabular}

Table 3 Comparison of the detection limit, response time, slope and $\mathrm{pH}$ range of various $\mathrm{Th}(\mathrm{IV})$ ion-selective electrodes

\begin{tabular}{|c|c|c|c|c|c|c|}
\hline & \multirow[b]{2}{*}{ Ref. 34} & \multicolumn{2}{|c|}{ Ref. 35} & \multirow[b]{2}{*}{ Ref. 36} & \multirow[b]{2}{*}{ Ref. 37} & \multirow{2}{*}{$\begin{array}{c}\text { This work } \\
\text { (CGE) }\end{array}$} \\
\hline & & $\begin{array}{c}\text { Homogenous } \\
\text { method }\end{array}$ & $\begin{array}{c}\text { Solid-solid } \\
\text { reaction }\end{array}$ & & & \\
\hline Detection limit/M & $5 \times 10^{-5}$ & $1.6 \times 10^{-6}$ & $5 \times 10^{-7}$ & $6 \times 10^{-6}$ & $8 \times 10^{-7}$ & $3.7 \times 10^{-8}$ \\
\hline Response time/s & $5-10$ & 30 & 30 & 15 & 10 & 8 \\
\hline Slope/mV decade de $^{-1}$ & 50 & $15.5 \pm 0.5$ & $16.5 \pm 0.5$ & 14.2 & $14.2 \pm 0.3$ & 15.1 \\
\hline pH range & $3-5$ & $3-5$ & $3-5$ & $2.5-9$ & $3.5-9.5$ & $3.15-6.5$ \\
\hline
\end{tabular}




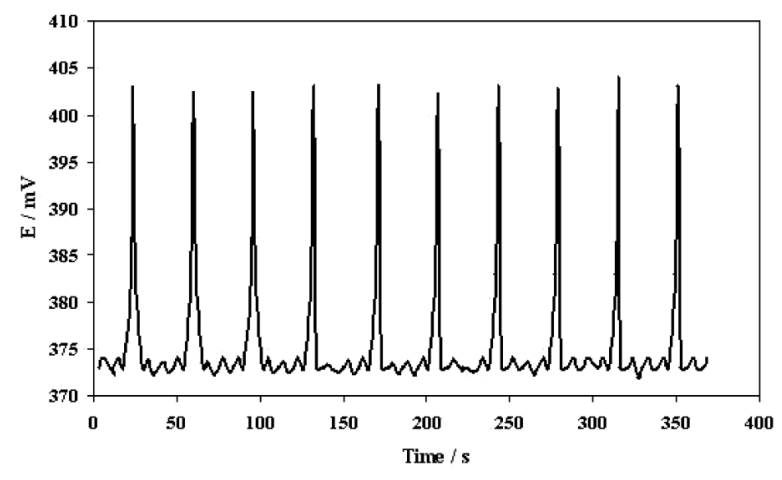

Fig. 6 Reproducibility of the flow-injection signals for 10 repetitive injections of a $1.0 \times 10^{-6} \mathrm{M}$ solution of $\mathrm{Th}^{4+}$.

emphasizing the superiority of the former electrode in this respect as well. ${ }^{31-35}$

Table 3 compares the detection limit, response time, slope and $\mathrm{pH}$ range of the proposed CGE with the previously reported thorium electrodes. ${ }^{36-39}$ The results clearly indicate the superiority of the proposed electrode in terms of the detection limit and the response time.

\section{FIP with CGE}

In the next step, the proposed $\mathrm{Th}^{4+}$-selective $\mathrm{CGE}$ was successfully used as a suitable indicator electrode in the flow-injection system shown in Fig. 2. The flow cell was made from polyamide in our laboratory. It contained a cylindrical solution path of $2.5 \mathrm{~mm}$ in diameter and of $1.5 \mathrm{~cm}$ in length; the effective volume of the cell was $74 \mu \mathrm{l}$. In order to achieve the best FIP response, several flow-injection parameters, including the tubing length, flow rate, sample volume, composition of the carrier solution and sampling rate, were thoroughly investigated.

The length of tubing from the injection valve port to the flow cell was kept as short as practically possible in order to minimize the dispersion and dilution. In this case, a 10-cm length was selected for the tubing. The dependency of the peak heights and the peak width, and the time to recover the base line on the flow rate was studied using the CGE response to a $1.0 \times 10^{-3} \mathrm{M}$ solution of thorium ion. The height of the relatively narrow response peaks was found to increase with increasing flow rate of the system up to almost a plateau at a flow rate of $30 \mathrm{~mL}$ $\min ^{-1}$. However, the peak widths began to increase considerably at flow rates higher than $30 \mathrm{~mL} \mathrm{~min}^{-1}$, at the expense of diminishing heights. Thus, this flow rate was selected as the optimum value for further studies.

In general, the peak heights increased with the increasing sample volume, although the effect was less marked at higher concentrations. ${ }^{40,41}$ For the proposed sensor, different sample volumes from 100 to $500 \mu \mathrm{L}$ were studied; the peak height reached nearly $100 \%$ of its maximum value at $150 \mu \mathrm{L}$ injected. Thus, this sample volume was selected as the optimum amount.

It is well-known that, in FIP, the composition of the carrier solution also affects the response behavior of an ion-selective electrode in terms of the base-line stability. ${ }^{42}$ In the proposed flow system, a $0.01 \mathrm{M} \mathrm{KNO}_{3}$ solution was used as a carrier, which resulted in good stable base lines, when samples were injected in the concentration range of $2.0 \times 10^{-7}$ to $1.0 \times 10^{-2} \mathrm{M}$. In analytical flow systems, the sampling rate (sample throughput) is also an important factor, representing the capability of the system in online analysis. The proposed potentiometric FIA system revealed sampling rates higher than 150 injections per

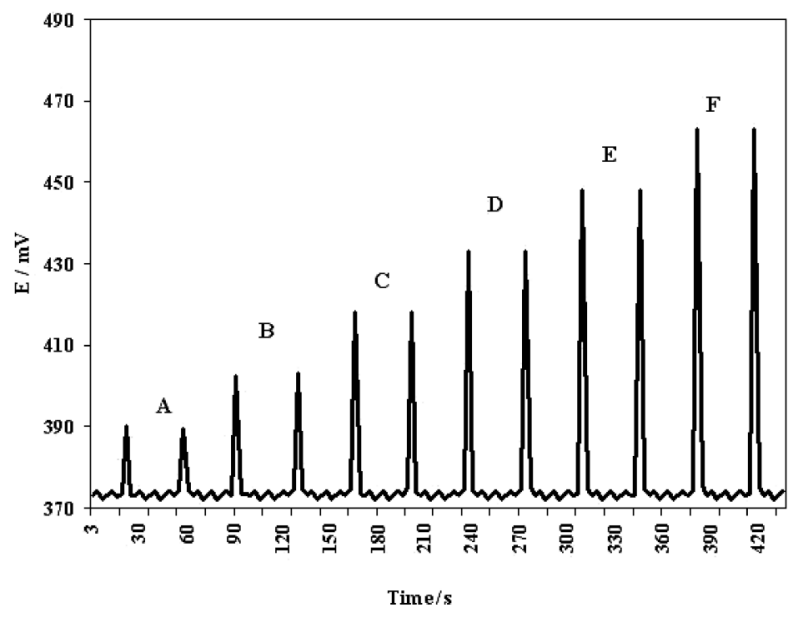

Fig. 7 Potentiometric peaks for two repetitive measurements of different $\mathrm{Th}^{4+}$ ion oncentrations: (A) $2.0 \times 10^{-7}$, (B) $1.0 \times 10^{-6} \mathrm{M}$, (C) $1.0 \times 10^{-5} \mathrm{M}$, (D) $1.0 \times 10^{-4} \mathrm{M}$, (E) $1.0 \times 10^{-3} \mathrm{M}$, (F) $1.0 \times 10^{-2} \mathrm{M}$.

hour.

The repeatability of the proposed CGE in the flow-injection system under the optimized conditions was checked by 10 repetitive injections of a $1.0 \times 10^{-6} \mathrm{M}$ solution of $\mathrm{Th}^{4+}$ ion; the results are shown in Fig. 6. The relative standard deviation of the peak heights (\%RSD) for six replicate injections of $1.0 \times 10^{-6} \mathrm{M}$ solutions of $\mathrm{Th}^{4+}$ was found to be $1.0 \%$. Figure 7 shows the peaks from the proposed FIP system obtained under the optimal experimental conditions for varying concentrations of $\mathrm{Th}^{4+}$ in the range of $1.0 \times 10^{-7}$ to $1.0 \times 10^{-2} \mathrm{M}$ concentrations. The corresponding emf-pTh ${ }^{4+}$ plot is also included in Fig. 4. As can be seen from Fig. 4, the calibration curve is quite linear over a wide concentration range of $1.2 \times 10^{-7}$ to $1.0 \times 10^{-2} \mathrm{M}$ with a slope of $13.9 \mathrm{mV}$ decade $^{-1}$ and a very low detection limit of $9.0 \times 10^{-8} \mathrm{M}$.

\section{Analytical applications}

The proposed $\mathrm{Th}^{4+}$ ion-selective electrode was found to work well under laboratory conditions. It was successfully applied to the determination of thorium in both standard and natural samples. With the use of the membrane sensor's calibration curve, the thorium contents in a monazite sand sample from triplicate measurements with electrode were found to be in satisfactory agreement with that determined by atomic absorption spectrometry (amounts determined by the ISE method, the AAS method and the recovery relative to AAS results were $1.41 \pm 0.3 \mathrm{ppm}, \quad 1.44 \pm 0.2 \mathrm{ppm}$ and $97.9 \%$, respectively).

The CGE was also used as an indicator electrode in the titration of the $\mathrm{Th}^{4+}$ ion with EDTA. The results of the titration of $25 \mathrm{~mL}$ of $1.0 \times 10^{-4} \mathrm{M}$ solution of $\mathrm{Th}^{4+}$ ion with a $1.0 \times$ $10^{-2} \mathrm{M}$ EDTA at $\mathrm{pH} 3.8$ revealed that the potential of the electrode decreased upon the addition of the EDTA solution, showing a sharp inflection at the titration end point. It was clearly found that the concentration of thorium ion in solution could be accurately determined from the resulting neat titration curve, providing a quite sharp end point.

\section{Conclusions}

A selective thorium(IV) polymeric membrane (PME) and CGE 
electrodes based on diphosphoryl-dicarboxylicacid-p-tertbutylcalix[4]arene (L) were constructed and applied to FIP. The sensor showed high selectivities and advanced response characteristics with a relatively fast response time, a wide linear concentration range of $2.0 \times 10^{-7}-1.0 \times 10^{-2} \mathrm{~mol} \mathrm{~L}^{-1}$ and a low detection limit of $9.0 \times 10^{-8} \mathrm{M}$. The observed selectivity could be related to the high tendency of the two P-donor atoms in addition to a number of donating oxygens, the ligand structure together with a proper cavity size provided by the structural conformation of the calix[4]arene derivative L. Another determining property which leads to the applicability of $\mathrm{L}$ as a proper ion carrier, is the relatively fast exchange kinetics that governs the formation of its $\mathrm{Th}^{4+}$ complex. The best PVC membrane electrode performance was achieved by a membrane composition of 5\% L, 33\% PVC, 59\% DOP and 3\% NaTPB.

\section{References}

1. S. Zhang, P. Liu, and B. Zhang, World Nucl. Geo. Sci., 2005, 22, 98 .

2. D. Humelnicu, G. Drochioiu, M. I. Sturza, A. Cecal, and L. K. Popa, J. Radioanal. Nucl. Chem., 2006, 270, 637.

3. M. Tamada, N. Seko, and F. Yoshii, Radiat. Phys. Chem., 2004, 71, 223.

4. T. P. Rao, P. Metilda, and J. M. Gladis, Talanta, 2006, 68, 1047.

5. D. Amman, W. E. Morf, P. Anker, P. C. Meier, E. Pretsch, and W. Simon, Ion Sel. Electrode Rev., 1983, 5, 3.

6. H. A. Arida, M. A. Ahmed, and A. M. El-Saied, Sensors, 2003, 3, 424.

7. S. Chandra, H. Agarwal, and C. K. Singh, Anal. Sci., 2007, $23,469$.

8. R. M. Izaff, J. S. Bradshaw, S. A. Nielson, J. D. Lamb, J. J. Christensen, and D. Son, Chem. Rev., 1985, 85, 271.

9. R. M. Izaff, K. Pawalk, J. S. Bradshaw, and R. L. Braening, Chem. Rev., 1991, 91, 1721.

10. M. Shamsipur, F. Mizani, M. F. Mousavi, N. Alizadeh, K. Alizadeh, H. Eshghi, and H. Karami, Anal. Chim. Acta, 2007, 589, 22.

11. M. Shamsipur, F. Mizani, K. Alizadeh, M. F. Mousavi, V. Lippolis, A. Garau, and C. Caltagirone, Sens. Actuators, B, 2008, 130, 300.

12. M. Shamsipur, F. Mizani, A. A. Saboury, H. Sharghi, and R. Khalifeh, Electroanalysis, 2007, 19, 587.

13. M. R. Ganjali, F. Mizani, M. Salavati-Niasari, and M. Javanbakht, Anal. Sci., 2003, 19, 235.

14. M. R. Ganjali, F. Mizani, M. Emami, M. Darjezini, M. Raouf Darvish, and M. Yousefi, Anal. Sci., 2004, 20, 531.

15. C. Dieleman, S. Steyer, C. Jeunesse, and D. Matt, Dalton, 2001, 2580.

16. M. Shamsipur, S. Rouhani, M. R. Ganjali, H. Sharghi, and H. Eshghi, Sens. Actuators, B, 1999, 59, 30.
17. M. Javanbakht, M. R. Ganjali, H. Eshghi, H. Sharghi, and M. Shamsipur, Electroanalysis, 1999, 11, 81.

18. M. Shamsipur, S. Rouhani, H. Sharghi, M. R. Ganjali, and H. Eshghi, Anal. Chem., 1999, 71, 4983.

19. M. Shamsipur, G. Khayatian, S. Y. Kazemi, K. Niknam, and H. Sharghi, J. Inclusion Phenom., 2001, 40, 303.

20. M. Shamsipur, S. Y. Kazemi, H. Sharghi, and K. Niknam, Fresenius J. Anal. Chem., 2001, 371, 1104.

21. M. Shamsipur, S. Rouhani, T. Poursaberi, M. R. Ganjali, H. Sharghi, and K. Niknam, Electroanalysis, 2002, 14, 729.

22. M. Shamsipur, S. Y. Kazemi, K. Niknam, and H. Sharghi, Bull. Korean Chem. Soc., 2002, 23, 53.

23. E. Bakker, P. Bühlmann, and E. Pretsch, Chem. Rev., 1997, 97, 3083.

24. X. Yang, N. Kumar, H. Chi, D. B. Hibbert, and P. N. W. Alexandr, Electroanalysis, 1997, 9, 549.

25. P. M. Gehrig, W. E. Morf, M. Weltic, E. Pretsch, and W. Simon, Helv. Chim. Acta, 1990, 73, 203.

26. R. Eugster, P. M. Morf, U. Spichiger, and W. Simon, Anal. Chem., 1991, 63, 2285.

27. T. Rostzin, E. Bakker, K. Suzuki, and W. Simon, Anal. Chim. Acta, 1993, 280, 197.

28. R. Eugster, U. E. Spichiger, and W. Simon, Anal. Chem., 1993, 65, 689.

29. IUPAC Analytical Chemistry Division, Commission on Analytical Nomenclature, Pure Appl. Chem., 1976, 48, 127.

30. Y. Umezawa, K. Umezawa, and H. Sato, Pure Appl. Chem., 1995, 67, 507.

31. Y. K. Lee, J. T. Park, C. K. Kim, and K. J. Whang, Anal. Chem., 1986, 58, 2101.

32. P. Bühlmann, S. Yajima, K. Tohka, K. Umezawa, S. Nishizawa, and Y. Umezawa, Electroanalysis, 1995, 7, 811.

33. M. K. Amini, S. Shahrokhian, and S. Tngestaninejad, Analyst, 1999, 124, 1319.

34. P. Schnierle, T. Kappes, and P. C. Hauser, Anal. Chem., 1998, 70, 3585.

35. M. Shamsipur, M. Yousefi, M. Hosseini, M. R. Ganjali, H. Sharghi, and H. Naeimi, Anal. Chem., 2001, 73, 2869.

36. S. K. Mittal and P. P. Singh, Indian J. Chem., 1995, 34A, 1009.

37. H. A. Arida, M. A. Ahmed, and A. M. El-Saied, Sensors, 2003, 3, 424.

38. S. Chandra, H. Agarwal, C. K. Singh, S. K. Sindhu, and P. Kumar, Indian J. Chem., 2005, 4A, 2060.

39. S. Chandra, H. Agravel, and C. Kumar Singh, Anal. Sci., 2007, 23, 469.

40. M. Shamsipura, A. Shirmardi Dezaki, M. Akhond, H. Sharghi, Z. Paziraee, and K. Alizadeh, J. Hazard. Mater. 2009, 172, 566.

41. X. Yang, N. Kumar, H. Chi, D. B. Hibbert, and P. N. W. Alexander, Electroanalysis, 1997, 9, 549.

42. X. Yang, D. B. Hibbert, and P. W. Alexander, Anal. Chim. Acta, 1998, 372, 387. 